\title{
Análisis del color y el soleamiento en las Torres de Quart de Valencia (España)
}

\author{
Analysis of colours and sun exposure in the Towers of \\ Quart in Valencia (Spain)
}

A. $\operatorname{Torres}^{(*)}$, J. Serra ${ }^{(*)}$, L. Llopis $^{(*)}$, J. L. Higón ${ }^{(*)}$, A. García ${ }^{(*)}$, B. Sáiz ${ }^{(*)}$

\section{RESUMEN}

En las Torres de Quart (s. XV) de la ciudad de Valencia, se ha desarrollado un exhaustivo trabajo de medición cromática de los restos de pigmentos existentes en las fachadas extramuros del edificio, sobre tres estratos materiales de distinta naturaleza. Asimismo, se ha estudiado la incidencia de la luz solar sobre las superficies del edificio.

Se describe y justifica el proceso llevado a cabo para la obtención de un documento gráfico preciso del estado del color y su iluminación que permita establecer un protocolo de actuación para intervenir en el monumento.

\section{SUMMARY}

In the Towers of Quart (s. XV) in the city of Valencia (Spain), an exhaustive chromatic measurement has been done of the remains of colour pigment found on the three distinct materials used in the external facade walls. The sun lighting exposure on the building surfaces has also been studied.

The paper describes and justifies the process for making an accurate study of the state of the colour and its illumination by the sun, which enables guidelines to be established for renovation works on the monument.

Keywords: Building materials; heritage; restoration; colour; sun exposure.
Palabras clave: Materiales de construcción patrimonio; restauración; color; soleamiento.
128-86

\footnotetext{
(*) Universitat Politècnica de València (España). Persona de contacto/Corresponding author: jllopis@ega.upv.es (J. Llopis).
} 
1. Ubicación de las Torres de Quart de Valencia (España).

2. Plantas y secciones de las Torres de Quart:

2.1. Sección longitudinal.

2.2. Sección transversal por torre sur.

2.3. (De izquierda a derecha): Planta 3, planta 2, planta 1 y planta baja.

\section{INTRODUCCIÓN HISTÓRICA Y DESCRIPCIÓN DEL EDIFICIO}

Las Torres de Quart son una de las puertas del recinto amurallado de Valencia de 1400 y se encuentran ubicadas en su flanco oriental (Figura 1). El diseño original de la obra es de Francesc Baldomar, pero su construcción se dilata en el tiempo, siendo Pere Bonfill quien finaliza su construcción en 1469 . Francesc Baldomar introduce una novedosa técnica para la estereotomía de las fábricas pétreas que hablan de una intencionada voluntad de estilo, así como una exhibición de virtuosismo constructivo (1). En el caso de las Torres de Quart la planta de los volúmenes se alinean en esviaje con el lienzo de la muralla, orientados respecto al antiguo camino que conduce a la población de Quart de Poblet, esviaje que provoca una complejidad añadida en la factura de los abovedamientos y vanos, y que convierte al edificio en una construcción de alto valor arquitectónico y constructivo (Figura 2).
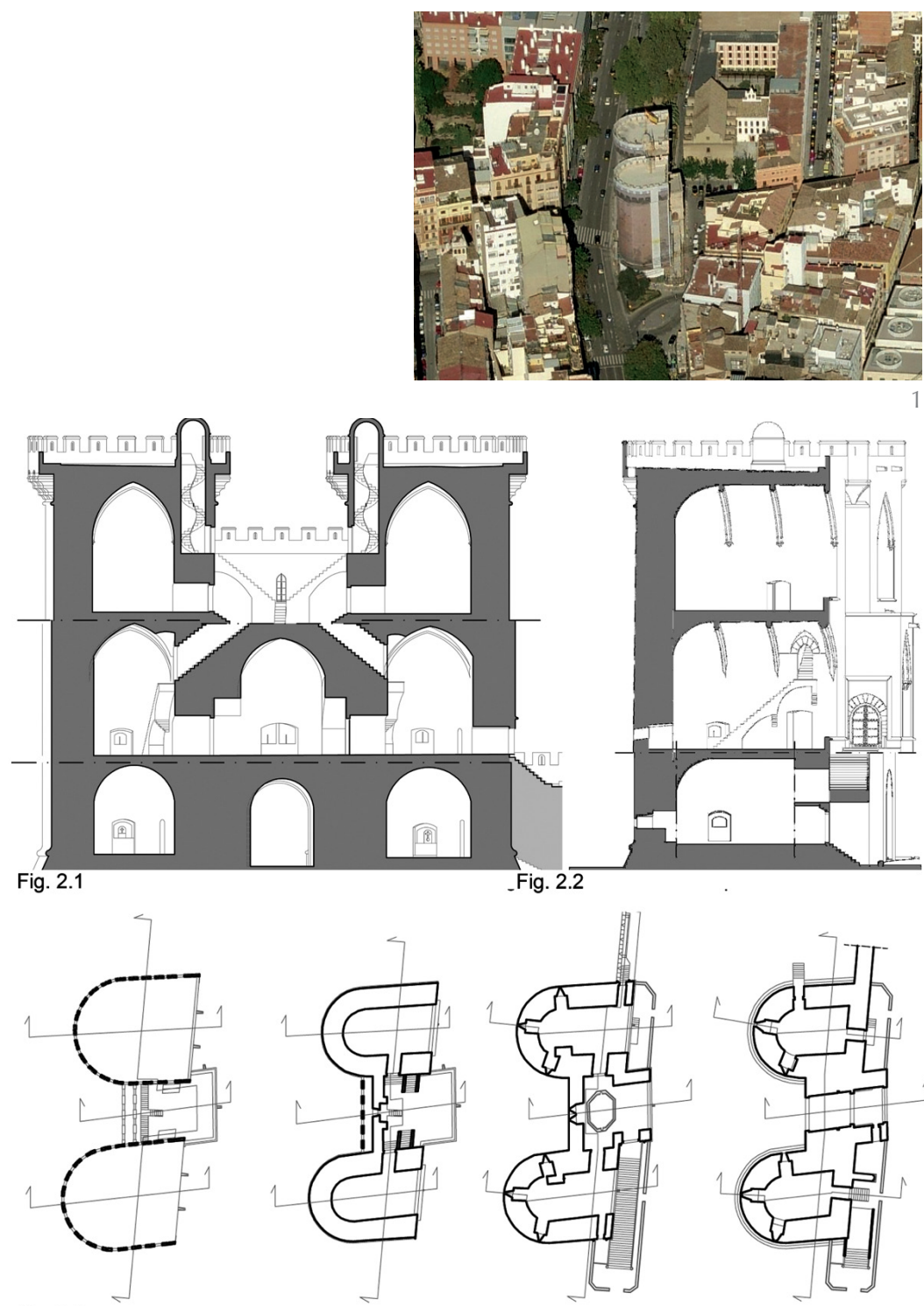

El edificio se compone de tres cuerpos arquitectónicos claramente diferenciados: la torre norte, el portal de acceso y la torre sur. Ninguno de ellos presenta restos de color en las fachadas orientadas hacia la ciudad. Las fachadas extramuros, sin embargo, están revestidas con dos tipos de mortero que en su momento se encontraban coloreados, y es en ellas donde se realizan las labores de identificación cromática.

El sistema constructivo consta de gruesos muros de tapial enlucidos con mortero liso de cal y sillares de piedra en los ángulos, aristas, bóvedas y coronación. Sus almenas se reconstruyen en piedra caliza de Godella en la rehabilitación Ilevada a cabo por D. Carlos Soler en los años cincuenta. En la última restauración por Emilio Rieta y Román Jiménez (1976-1982), se construye la monumental escalinata exterior con sillares procedentes del palacio de los condes de Parcent.

El proyecto de restauración de las Torres de Quart es una actuación promovida por la Concejalía de Cultura del Excmo. Ayuntamiento de Valencia. Se lleva a cabo durante el año 2007 y se enmarca dentro del plan de embellecimiento de la ciudad con vistas a la competición de vela de la $32^{\text {nd }}$ America's Cup.

El presente artículo expone la metodología y conclusiones del estudio desarrollado por el Grupo de Color, Fotogrametría, Levantamientos y Análisis Gráfico para la Arquitectura histórica, que pertenece al Instituto de restauración del Patrimonio de la Universidad Politécnica de Valencia, en el marco de dichos trabajos de restauración. En dicha actuación se propuso desarrollar un estudio global de los revestimientos originales, tanto en lo relativo a la composición original de los mismos, como en lo referente al cromatismo original. Dicho estudio incluía la determinación de las características cromáticas originales, así como un estudio de las condiciones de degradación cromática al que estaban expuestas las Torres de Quart y su relación con el soleamiento, analizando la degradación del mortero original en relación con la diferente exposición solar de cada cara, con el objetivo de desarrollar una propuesta de actuación que respetase el cromatismo original, y dotase a la intervención de unas condiciones de durabilidad suficientes.

\section{MATERIALES Y MÉTODO}

Dadas las heterogéneas condiciones de preservación de las características cromáticas del mortero original, la enorme superficie muraria objeto de análisis, y las varia- 
bles condiciones de exposición ambiental de las diferentes áreas superficiales del edificio, resulta imposible la determinación de sus características cromáticas por medición directa en un número limitado de puntos de control. En estas condiciones, la medición cromática ha de ser, necesariamente, de carácter estadístico. De hecho, la hipótesis de partida, que como veremos al final del análisis quedó suficientemente corroborada, es que dada la imposibilidad de determinar el color original a partir de una serie limitada de mediciones cromáticas puntuales, se podía establecer una estrategia de carácter "zonal", subdividiendo la superficie total en áreas de trabajo en las que calcular la media de las mediciones cromáticas, entendiendo dicho valor resultante como una aproximación suficiente al color global de toda el área.

Siguiendo esta estrategia, y con el fin de organizar el proceso de medición cromática que se va a extraer del edificio, la totalidad de las fachadas extramuros se subdividen en una serie de cuadrantes mediante el empleo de una retícula rectangular de anchura $1,4 \mathrm{~m}$ y altura $1 \mathrm{~m}$, lo que genera un total de 1.664 paños de control cromático. Esta subdivisión se adopta de acuerdo a dos criterios que consideramos válidos en la hipótesis inicial: En primer lugar entendemos que dadas las degradadas condiciones de conservación, áreas más pequeñas carecerían de un valor estadístico suficiente; mientras que áreas más grandes generarían un número insuficiente de áreas en las que desarrollar una medición con validez estadística. En segundo lugar, las dimensiones de la división planteada son coherentes con el sistema de andamiajes erigido en obra, lo que facilita el proceso de medición en su conjunto desde el punto de vista práctico.

Como punto de partida del trabajo se considera que cada cuadrante establecido es una unidad cromática uniforme e indivisible a la que corresponden, por tanto, unos parámetros colorimétricos únicos. La aproximación es suficientemente exacta ya que no se esperan alteraciones de color significativas en menos de $1,35 \mathrm{~m}^{2}$, como efectivamente así se evidencia a la luz de los resultados (Figura 3).

Este conjunto de cuadrantes responde a las diferentes condiciones de exposición al medio de las superficies del edificio. El objetivo es determinar si existe una relación entre la degradación cromática y parámetros tales como la orientación respecto al sol (y consecuente con la intensidad de la radiación solar soportada), su posición relativa respecto a la calle (mayor o menor exposición a las agresiones del tráfico...), y su posición relativa respecto a las diferentes tecnologías materiales de las torres (paramento murario de piedra...)

\subsection{Metodología de la analítica de los morteros y de las mediciones cromáticas}

Una vez codificado cada cuadrante de fachada se miden los valores cromáticos de cuantos restos significativos se encuentren. Como cabe esperar, la distribución de estos fragmentos de color no es isótropa y por tanto el número de medidas realizadas en cada cuadrante es desigual, obteniéndose un número medio de 2,8 muestras en cada uno. Este valor medio ha estado determinado por las condiciones de degradación del propio mortero de acabado, y es el resultado medio del total, de manera que en ocasiones el estado de conservación ha permitido un número mayor de muestras y mediciones, mientras que en otras ocasiones ha sido imposible desarrollar dicho trabajo de análisis. Piénsese a este respecto que en los paramentos inferiores, más sometidos a la degradación que los superiores, ha sido prácticamente imposible efectuar medición alguna, bien por el deficiente estado de conservación, bien por haber sido sometidos a procesos parciales de consolidación posterior. Por el contrario, las barbacanas correspondientes a la coronación de las torres protegen un número importante de restos de color, ya que se han visto menos expuestas a los agentes atmosféricos. Esto supone, en definitiva, una medición del color aproximada cada $70,7 \mathrm{~cm}$. a lo largo de toda la fachada.

\begin{tabular}{|l|l|}
\hline Muestra & TN/6/G/III_M2 \\
\hline Color Sist. Munsell & 7,5 YR/ 4/ 4 \\
\hline Color X, Y, Z & $13.26 / 12 / 6.25$ \\
\hline Color CIE L*ab & $41.22 / 9.98 / 23.60$ \\
\hline Aproximación RGB & $123 / 90 / 61$ \\
\hline Muestra aproximada & \\
\hline
\end{tabular}

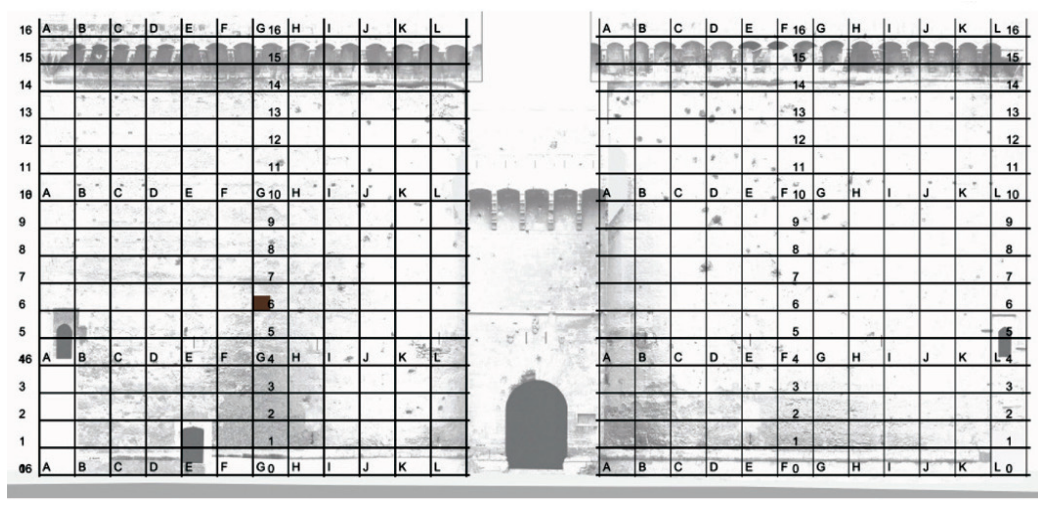

3. Identificación de dos muestras de color tomadas en la torre norte, sobre el mortero 2, posición en el alzado y caracterización cromática. altura 6, cuadrante G, sección III, 

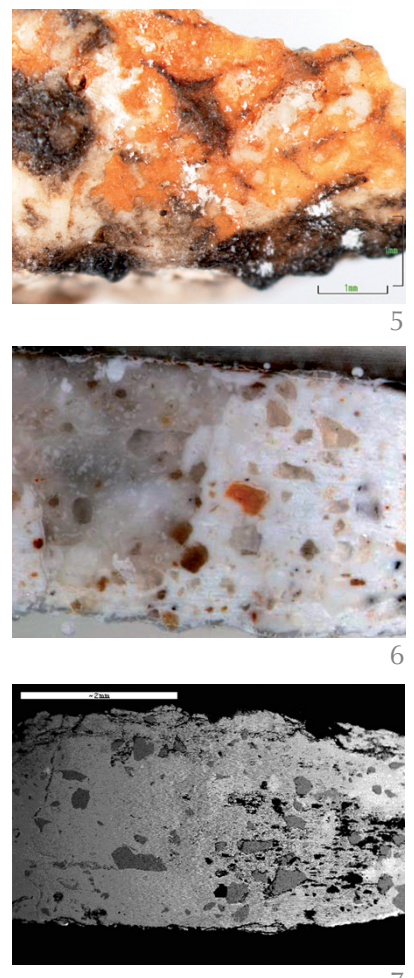

4. Difractograma de los compuestos cristalinos mayoritarios de la muestra analizada. Muestra QM6.

5. Superficie de la muestra bajo lupa binocular.

6. Sección transversal de la muestra a $45 X$.

7. Microfotografía obtenida por MEB a $25 X$.

8. Microanálisis obtenido por EDX.

9. Microanálisis obtenido por EDX.

Sample ident. : $0-M 6$

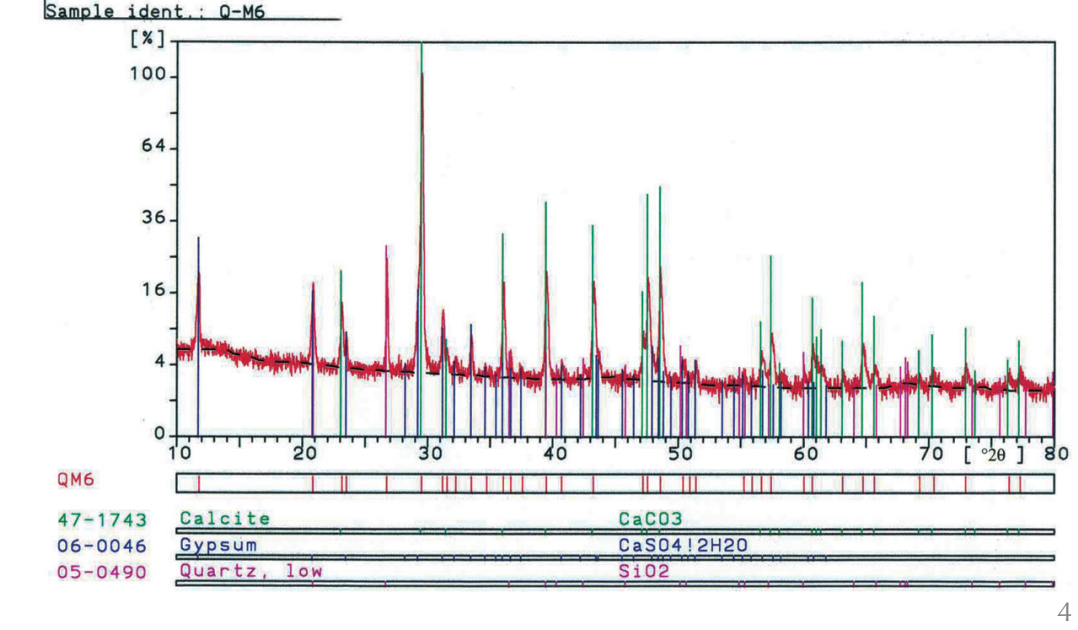

Respecto a las condiciones materiales iniciales de cada área de análisis hay que hacer constar que los restos de pigmentos encontrados se ubican sobre 3 tipos de materiales diferenciados: piedra de caliza (en adelante piedra) y dos niveles de mortero de cal de distinta antigüedad (en adelante M1 y M2) de composición similar a los que se empleaban en las fachadas de la arquitectura popular del centro histórico de Valencia (2). La determinación de las características compositivas de los morteros encontrados, se ha realizado en base a las técnicas de análisis que a continuación se describen.

El estudio de la composición físico-química de los morteros y de las capas de policromía se ha realizado mediante Difracción de Rayos-X (DRX), Microscopía Óptica (MO) y Microscopía Electrónica de Barrido con microanálisis por dispersión de energías de rayos-X (MEB/EDX). El mortero M1 se identifica como un mortero de cal con áridos de sílice, coloreado en superficie con tierras naturales. El difractograma de rayos-X de la muestra QM6, (Figura 4), procedente de la torre sur y extraída a nivel de mortero M1, determina como compuestos mayoritarios del mortero a la calcita y el cuarzo, con presencia minoritaria de yeso de neoformación. Estos resultados se corroboran en el microanálisis de rayos- $X$ realizado en $\mathrm{MEB} /$ EDX de la muestra QM2, (Figuras 8 y 9).

Los restos de pintura analizados a nivel de mortero M1, procedentes de la muestra QM2, muestran la presencia de tierras a base de alumino-silicatos y óxidos de hierro, no apreciándose coloración en masa, (Figuras 5, 6 y 7).

La analítica realizada sobre la muestra QM16, obtenida a nivel de mortero 2 en la torre norte se identifica como un mortero de cal con capa de yeso de neo-formación, atribuido al efecto de la contaminación (Figura 10), y una capa rojiza coloreada en superficie.
El difractograma de rayos-X de la Figura 11, perteneciente a la muestra de la Torre Norte QM41 y extraída a nivel de mortero 2, muestra que los principales compuestos cristalinos detectados son calcita y cuarzo detectándose también dolomita, hematites y yeso en menor proporción, confirmando que el mortero 2 es un mortero de cal con árido silíceo y con presencia de óxido férrico (hematites), presente en la capa rojiza de policromía superficial.

Por su parte, las mediciones cromáticas se han Ilevado a cabo empleando un espectrofotómetro de contacto modelo Kónica Minolta CM-2600d, con sistema de iluminación esférico d/8 ${ }^{\circ}$, iluminante estándar CIE D65, reflectancia especular excluida (SCE), área de medida de $\varnothing=8 \mathrm{~mm}$ y sistema de notación del color Munsell (3). El tratamiento informático de la información cromática obtenida se ha desarrollado mediante el empleo del software Spectramagic NX, de la casa Kónica Minolta. La tecnología empleada en este proceso nos permite la determinación de las coordenadas cromáticas de la edificación en la actualidad, así como las diferencias de color, valores de color y cromaticidad, y los valores físicos de luz y humedad. Se garantiza así el carácter objetivo de la determinación de las gamas cromáticas originales, ordenadas y tipificadas de acuerdo al sistema Munsell de notación cromática. Entendemos que el empleo del sistema Munsell garantiza la objetividad científica de los resultados, y el carácter generalizable que otras cartas de carácter comercial no están en disposición de aportar.

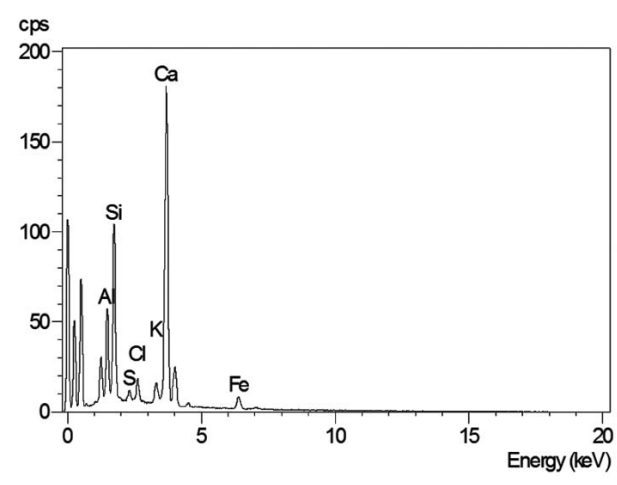

cps

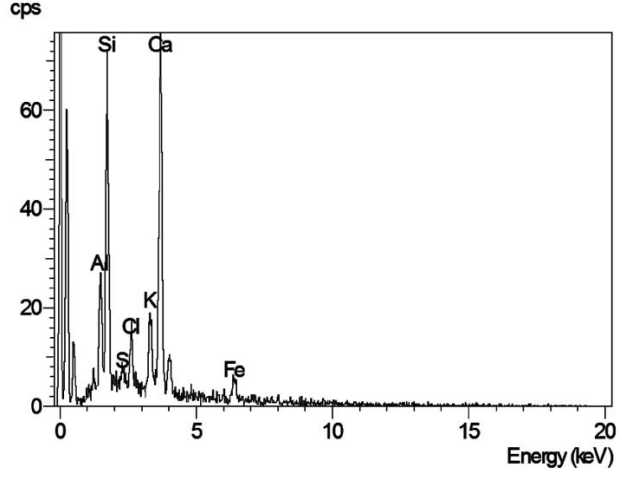




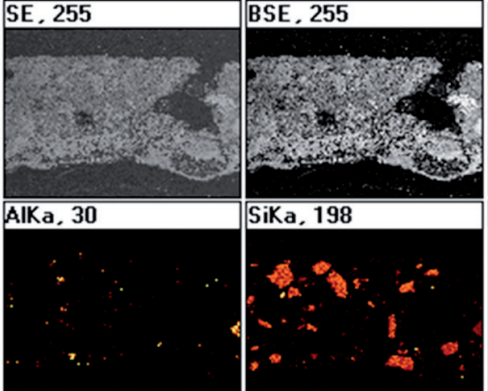

\subsection{Medición del soleamiento}

De forma simultánea al proceso de identificación de los restos pigmentados se desarrolla un modelo digital para el análisis de la incidencia de la luz solar sobre las fachadas del monumento objeto de estudio. Se pretende el cálculo de la cantidad de horas de sol que recibe cada punto de las superficies extramuros de las Torres de Quart a lo largo de todo un año. Para ello, se recurre a la confección de cinco "mapas de sombras". Un mapa de sombras es un documento gráfico obtenido mediante tratamiento informático de un modelo digital en tres dimensiones que, correctamente orientado respecto a la dirección del Norte geográfico y conociendo las circunstancias del entorno edificado, permite obtener un registro completo de la duración de la incidencia solar recibida por cada punto de la superficie del modelo. En su desarrollo interviene la progresiva variación de la inclinación del Sol respecto al objeto a medida que avanzan las horas del día y las estaciones del año.

El desarrollo de los mapas de sombra permite calcular el Ilamado Factor de Obstrucción Solar (en adelante: F) (4). Este factor F se define como la relación, punto a punto, entre la duración en horas del periodo no iluminado respecto de las horas totales consideradas, que son las correspondientes al periodo solar completo de un año. Dicho valor escalar genera un campo sobre las superficies expuestas al sol, de tal modo que puede adquirir un valor numérico comprendido entre 0 (punto siempre iluminado) y 1 (punto siempre en sombra). El producto resultante de multiplicar el Factor de Obstrucción por el número máximo anual de horas de sol permite obtener, para cada punto de la superficie del modelo estudiado, la duración del periodo de incidencia solar.

Para la confección de los mapas de sombra se propone un método gráfico basado en procedimientos informáticos. Asumiendo que los programas de CAD permiten obtener imágenes de sombras propias y arrojadas de modelos tridimensionales, puede organizarse una secuencia de imágenes que reproduce la variación anual del vector solar sobre las superficies del modelo.
10. Mapping correspondiente a la muestra QM16. La parte inferior de las imágenes corresponde con el exterior del muro.

11. Difractograma de los compuestos cristalinos mayoritarios de la muestra analizada. Muestra

QM41.
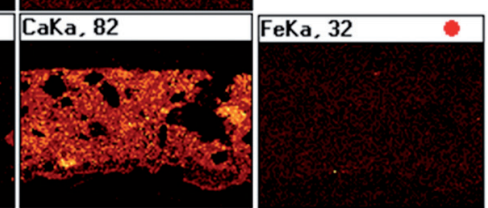

Sample ident. T0-M41

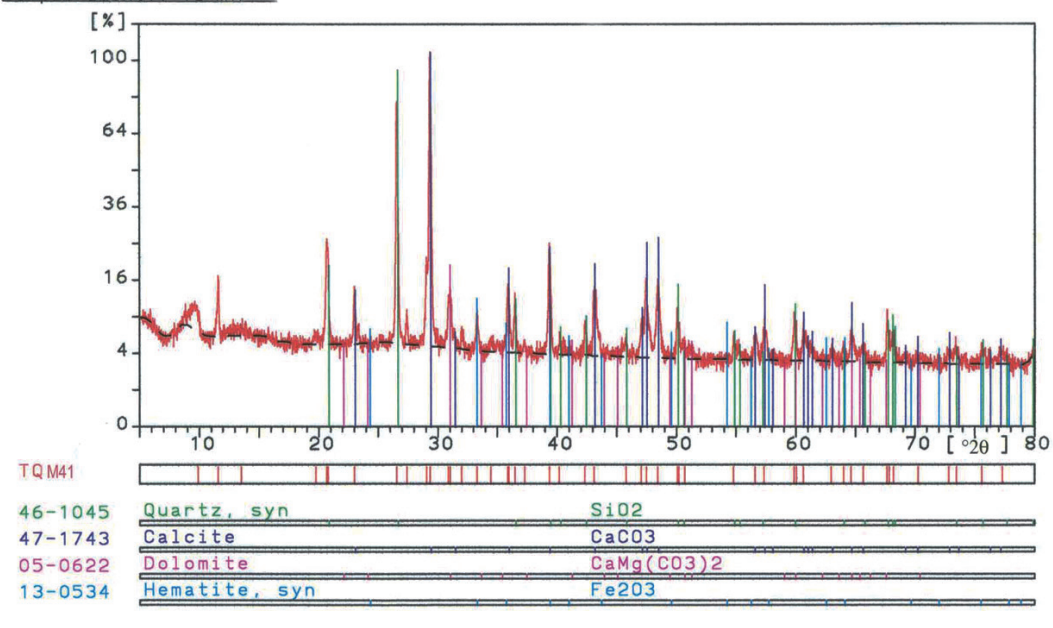

Las 5.082 imágenes obtenidas para el periodo anual proveen de datos que, una vez procesados y analizados, permiten la obtención de una imagen con los valores promediados de la secuencia. Sobre dicha "imagen promedio" se puede evaluar el valor de F para cualquier punto de la superficie del modelo.

El procedimiento para la obtención del Factor de Obstrucción Solar está basado en el análisis del valor de gris contenido en los píxeles de las "imágenes promedio" del periodo anual. La frecuencia con que un píxel concreto aparece en la imagen con un color negro (en sombra), o blanco (expuesto a la luz solar) permite calcular un valor de gris como media ponderada. El resultado gráfico es una imagen global de la que puede extraerse el valor numérico del factor de obstrucción solar correspondiente a cada píxel, así como su equivalencia en Horas de sol / año para las superficies del modelo. A efectos de hacer inteligible la variación del valor de F sobre la superficie del modelo, se intercalan en los mapas de sombras unas líneas que encierran puntos de igual valor del $\mathrm{F}$, lo que permite interpretar de modo visual la distribución de la luz solar a lo largo del año.

\section{RESULTADOS}

\subsection{Proporción y distribución de las muestras existentes}

En términos relativos y estudiando cada uno de los tres estratos coloreados, puede 
12. Distribución de las muestras a lo largo de la fachada extramuros.

13. Los deterioros físicos y las piedras no coloreadas representan un $46,3 \%$ de la superficie total de la fachada extramuros de las Torres de Quart. afirmarse que la mayor concentración de pigmento en el mortero 1 (M1) se produce en la torre Norte, la mayor concentración de pigmento en el mortero 2 de (M2) corresponde a la torre sur y la piedra coloreada es más significativa en el portal. En sentido vertical la distribución es sensiblemente uniforme en $\mathrm{M} 2$ y piedra, mientras que en $\mathrm{M} 1$ es significativamente mayor en pisos inferiores (Figura 12).

Esta variación en la distribución de las muestras viene muy determinada por los deterioros del mortero presentes a lo largo de la fachada. No debe olvidarse que las Torres de Quart se conciben como elemento defensivo de la ciudad y han resistido la embestida de numerosas invasiones que han afectado a la integridad de su fachada.

A los deterioros propios de los avatares históricos en un edificio de carácter defensivo debe sumarse otra importante cantidad de deterioros de distinto origen: morteros impropios, mechinales, alveolización, deterioros antrópicos, deterioros biológicos, eflorescencias, erosión, costra negra, humectaciones, lavados, alveolizaciones etc. Aspectos, todos ellos, que han provocado el deterioro físico de las superficies de mortero en un $45 \%$ en la torre Norte, y en un $35 \%$ en la torre Sur (Figura 13).

De la superficie total de la fachada extramuros se observa que no existe color en ninguno de los sillares de la barbacana almenada que remata el edificio, ya que se trata de una reconstrucción de la original Ilevada a cabo a finales del XVIII. Lo mismo ocurre con el basamento de apoyo de ambas torres, que corresponde a una intervención posterior y carece asimismo de pigmento. Los sillares que sí presentan restos de color son aquellos correspondientes al pórtico central y a las superficies protegidas bajo las bóvedas de las barbacanas de coronación; es decir, todos los sillares de la obra original del edificio, lo que parece indicar que la sillería estuvo inicialmente coloreada.

De la superficie total de fachada enfoscada originalmente $\left(1.540 \mathrm{~m}^{2}\right)$, se conserva el mortero en $930,94 \mathrm{~m}^{2}$; lo que supone un deterioro físico del $40 \%$ de su superficie, mientras que los 769 restos de pigmento encontrados sobre los morteros permiten deducir la información cromática del $47 \%$ del enfoscado conservado (438,2 $\left.\mathrm{m}^{2}\right)$.

\subsection{Tonalidades dominantes y su representación en fachada}

\subsubsection{Mortero 1 (M1)}

El estrato M1 es más antiguo que el M2 y se encuentra en un estrato inferior. Su medición se ha realizado exclusivamente en los casos en que se había deteriorado M2, de modo que se encontraba accesible a nivel superficial. Los restos de color encontrados sobre su superficie son doce veces inferiores a la porción coloreada en $M 2$, y representa un escaso $1,4 \%$ de la superficie total de mortero original. Su valoración cromática no es importante tanto por la cantidad de muestras halladas sino porque determina la existencia de dos tratamientos cromáticos diferenciados correspondientes a dos épocas cronológicas sucesivas.

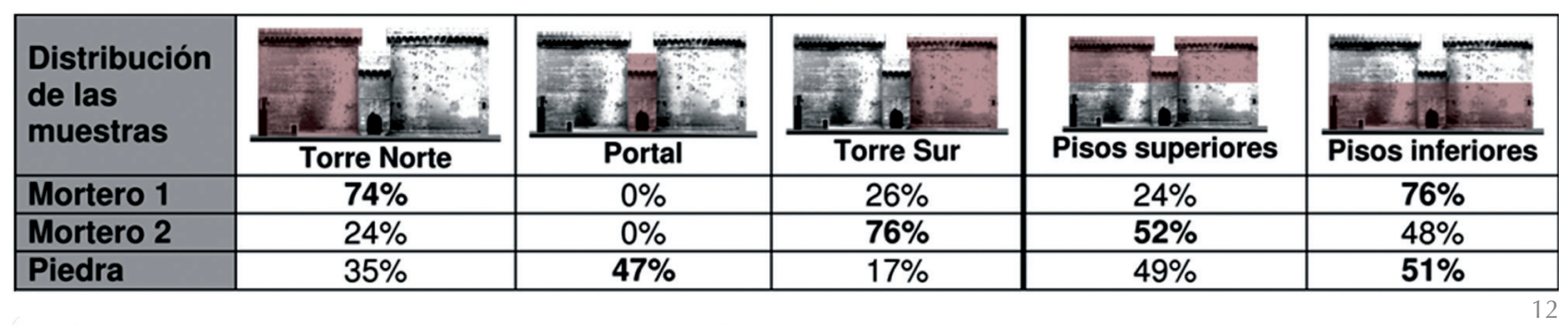

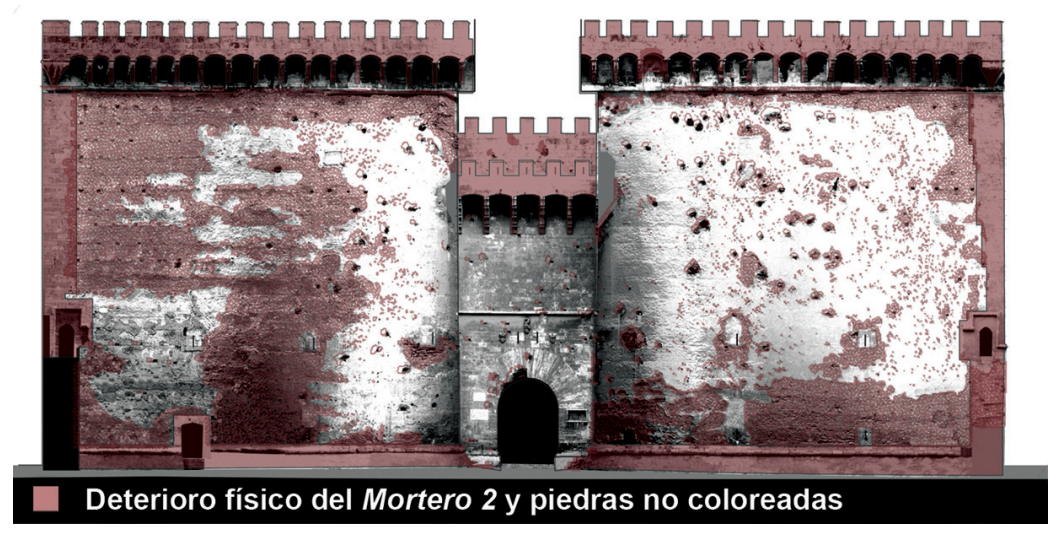

Las tonalidades dominantes en el estrato M1 corresponden a la familia de colores en notación Munsell 8 YR, en la que se observa una concentración del $32 \%$ de las muestras. Le siguen las familias 5,5 YR, $10 \mathrm{YR}$ y otras gamas propias de las familias YR, en menor proporción (Figuras 14 y 15). Los colores en notación Munsell han sido trasladados al sistema CIE Lab* (1976) para establecer la desviación estándar de cada parámetro cromático (5): Luminosidad $\left(\Delta \mathrm{L}^{*}\right)$; contenido de verderojo $\left(\Delta \mathrm{a}^{*}\right)$, y azul-amarillo $\left(\Delta \mathrm{b}^{*}\right)$. La media numérica obtenida de los restos cro- 
máticos existentes en $\mathrm{M} 1$ corresponde al color $\mathrm{L}^{*}=54.49, \mathrm{a}^{*}=7.75, \mathrm{~b}^{*}=21.93$ (8 YR/ 5.5/ 4 en notación Munsell). Aunque se trate solo de una aproximación matemática, las muestras de color obtenidas son muy coherentes con el resultado $\left(\Delta \mathrm{L}^{*}=7.60, \Delta \mathrm{a}^{*}=1.91, \Delta \mathrm{b}^{*}=2.55\right.$, diferencia de color $\Delta \mathrm{E}=8.24$ ). Existe una gran cantidad de muestras de color próximas a la media, y unas pocas muestras distantes, que aumentan la diferencia entre los valores máximo y mínimo para cada parámetro. Estas muestras lejanas a la media son muy escasas pero no pueden ser eliminadas de la población, pues pudieran estar, de algún modo, relacionadas con el color original.

\subsubsection{Mortero $2(\mathrm{M} 2)$}

El nivel M2 es el estrato coloreado más superficial, y por tanto el más actual. Recubre la mayor parte de la fachada extramuros y cuenta con una superficie significativa de restos cromáticos, lo que ha permitido hacer una medición muy extensa en número de muestras. do el mismo criterio que en el caso anterior obtenemos que la media numérica de los restos cromáticos existentes en $\mathrm{M} 2$ corresponde al color $\mathrm{L}^{*}=55.91, \mathrm{a}^{*}=8.55, \mathrm{~b}^{*}=23.61$ (8 YR/ 5.5/ 4 en notación Munsell). También en este caso las muestras de color obtenidas son muy coherentes con el resultado $\left(\Delta \mathrm{L}^{*}=7.63, \Delta \mathrm{a}^{*}=2.58, \Delta \mathrm{b}^{*}=3.83\right.$, diferencia de color $\Delta \mathrm{E}=8.92$ ) y se ha determinado la existencia de un escaso número de muestras que se alejan de la media.

\subsubsection{Piedra}

El estrato "piedra" se corresponde con los sillares de piedra caliza que rematan las esquinas de las torres, la fábrica sin enfoscar del pórtico central y alguna porción aislada de piedra a lo largo de la fachada. Sobre ella se han encontrado restos de pinturas aplicadas "in situ", que ocultaban el color natural propio del material. Estos restos de pigmentación se encuentran, en general, en un adecuado estado de conservación por pertenecer a lugares resguardados: caras inferiores de las impostas, esquinas de encuentro con las torres etc.
14. Proporción de colores en mortero M1 por familias de color en notación Munsell.

15. Aproximación de colores en mortero $\mathrm{M} 1$ a lo largo de la fachada extramuros.

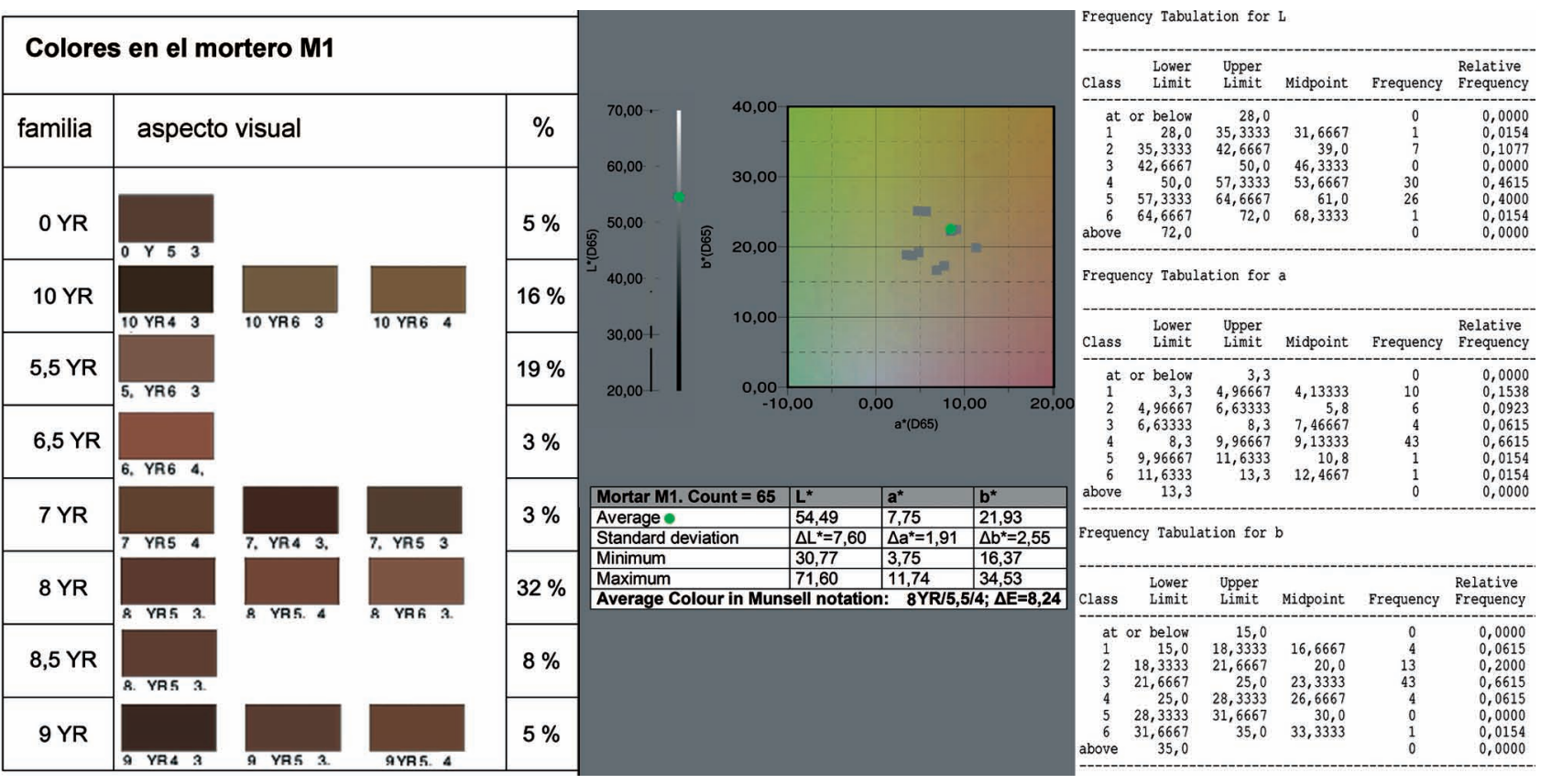

Si bien el color en M2 se ha podido deducir a partir de un número mayor de medidas que en $M 1$, su proximidad con el color original no es necesariamente más fiable si se tiene en cuenta que su superficie ha estado más expuesta a la intemperie y el soleamiento. Las tonalidades dominantes en el estrato M2 corresponden a la familia de colores en notación Munsell 7,5 YR, en la que se observa una concentración del $46 \%$ de las muestras. Le siguen las familias 10 YR, 8,5 YR y otras gamas propias de las familias $Y R$ en mucha menor proporción (Figuras 16 y 17). Aplican-

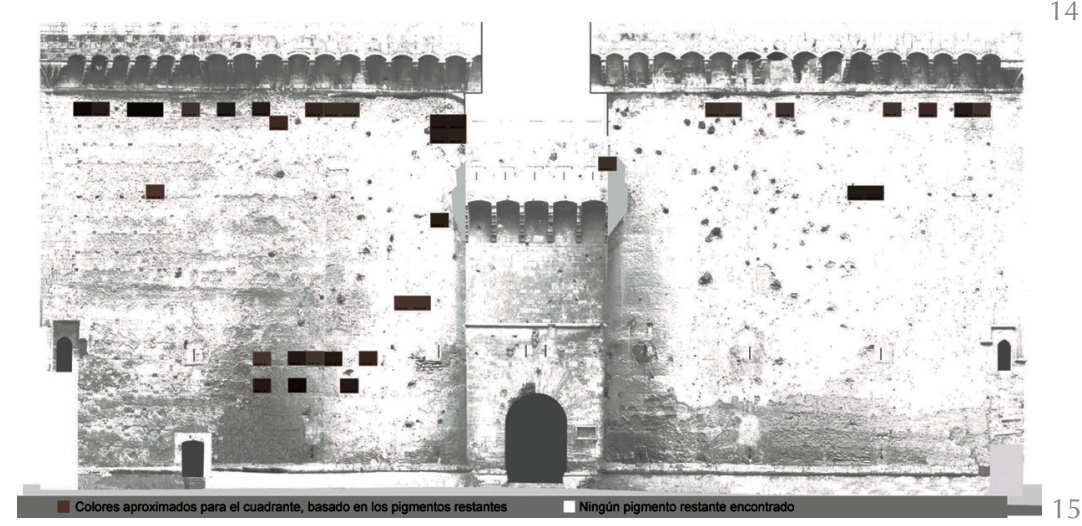


16. Proporción de colores en mortero M2 por familias de color, en notación Munsell.

17. Aproximación de colores en mortero M2 a lo largo de la fachada extramuros.

18. Proporción de colores en sustrato piedra organizados por familias de color en notación Munsell.

19. Aproximación de colores en sustrato piedra a lo largo de la fachada extramuros.
Son superficies pigmentadas de tamaño amplio y adecuado para ser medidas cromáticamente, y su proporción respecto a la superficie pétrea es elevada.

Las tonalidades dominantes sobre la piedra corresponden a la familia de colores en notación Munsell 7,5 YR, en la que se observa una concentración del $38 \%$ de las muestras. Le siguen las familias 7 YR, 6,5 YR, 6 YR y otras gamas propias de las familias $Y R$ en menor propor- ción, tal y como se representa en los cuadros correspondientes (Figuras 18 y 19). Trasladando los resultados obtenidos del Sistema Munsell al sistema CIE Lab* (1976) obtenemos que la media numérica de los restos cromáticos existentes corresponde al color $\mathrm{L}^{*}=49.64$, $a^{*}=9.05, b^{*}=19.19$ (7YR/ 5/ 4 en notación Munsell). También en este caso las muestras de color obtenidas son muy coherentes con el resultado $\left(\Delta \mathrm{L}^{*}=6.75, \Delta \mathrm{a}^{*}=2.35, \Delta \mathrm{b}^{*}=3.77\right.$, diferencia de color $\Delta \mathrm{E}=8.08$ ).

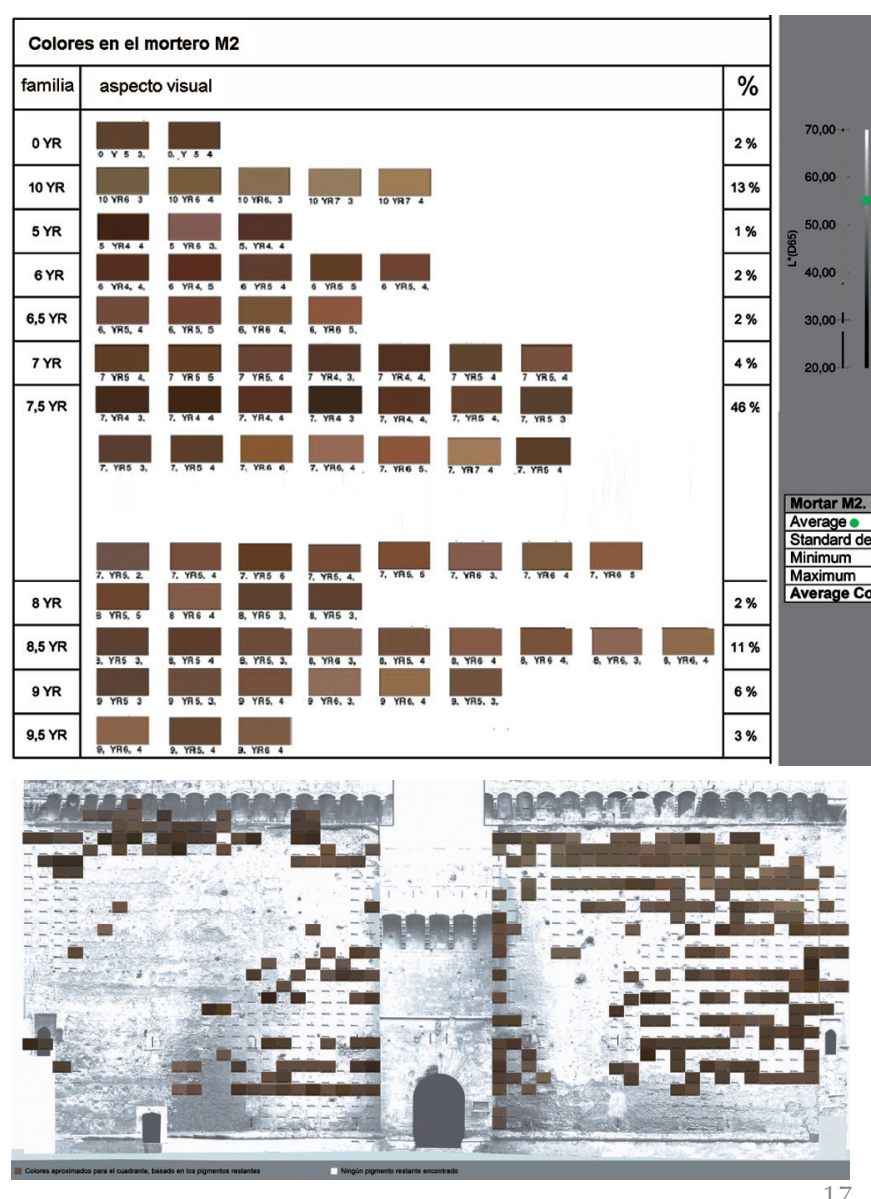

Colores en el material "Piedra"

\begin{tabular}{|c|c|c|}
\hline familia & aspecto visual & $\%$ \\
\hline $3,5 \mathrm{YR}$ & 3. VAA, 2. & $1 \%$ \\
\hline $4,5 \mathrm{YR}$ & & $3 \%$ \\
\hline $5 \mathrm{YR}$ & & $9 \%$ \\
\hline 5,5 YR & 3 & $9 \%$ \\
\hline $6 \mathrm{YR}$ & & $11 \%$ \\
\hline $6,5 \mathrm{YR}$ & ‘ & $11 \%$ \\
\hline $7 \mathrm{YR}$ & & $11 \%$ \\
\hline $7,5 \mathrm{YR}$ & & $38 \%$ \\
\hline $8 \mathrm{YR}$ & & $4 \%$ \\
\hline $8,5 \mathrm{YR}$ & 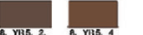 & $2 \%$ \\
\hline 9 YR & & $1 \%$ \\
\hline
\end{tabular}

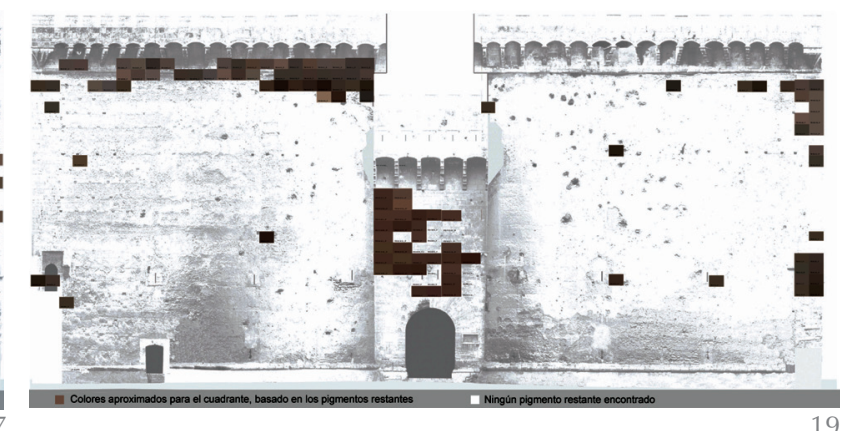

19

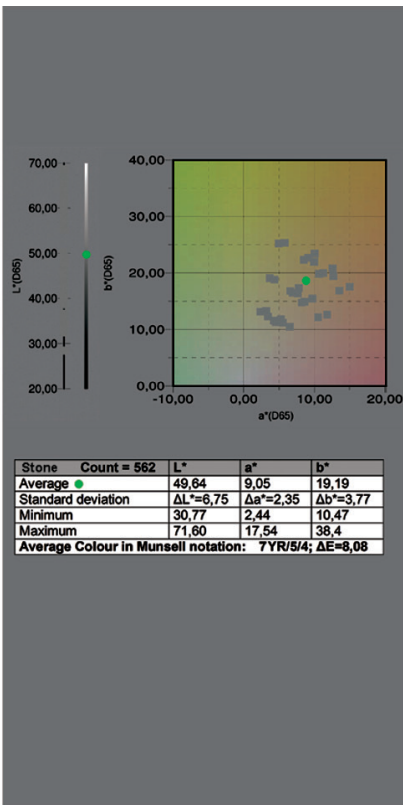

16 


\subsubsection{Barbacanas}

En este apartado se estudia el color presente en el intradós de las bóvedas de las barbacanas y en los laterales de sus ménsulas, donde se encuentran numerosos restos de pigmentos en un adecuado estado de conservación. Se trata de sillares de piedra coloreados, y por tanto, se espera de ellos unas medidas cromáticas similares a las del estrato de piedra del resto de la fachada, aunque se observará en ellas menor contenido del color primario rojo.

Las tonalidades dominantes sobre la piedra de las barbacanas corresponden a las familias de colores en notación Munsell 7,5 YR; 8 YR; 8, 5 YR; 9 YR en la que se observa una concentración del $74 \%$ de las muestras. Le siguen las familias 7 YR y otras gamas propias de las familias $Y R$ en mucha menor proporción (Figura 20).

Si atendemos a la representación espectral del color promedio obtenido, observamos una curva de pendiente ascendente, con valores de reflectancia elevados en las longitudes de onda largas, propias de los tonos anaranjados y rojizos (Figuras 21 y 22).

Si se traducen los valores obtenidos en el entorno de las barbacanas al espacio de color CIE L*ab (1976), se obtiene el color promedio de los restos de color en las barbacanas y coinciden con el color $\mathrm{L}^{*}=52.19$, $\mathrm{a}=6.75, \mathrm{~b}=16.51$ (8 YR / $5 / 3$ en notación Munsell). Se trata de una aproxima- ción muy exacta, aún más exacta que en los estratos anteriores $\left(\Delta \mathrm{L}^{*}=6.00, \Delta \mathrm{a}^{*}=1.87\right.$, $\Delta \mathrm{b}^{*}=3.72$, diferencia de color $\Delta \mathrm{E}=7.3$ ). Nuevamente aquí se mantiene el criterio de mantener los valores de las muestras lejanas a la media hasta su análisis posterior.

\subsection{Mapa de Sombras}

El análisis de los mapas de sombra obtenidos permite valorar la incidencia del sol sobre las superficies de fachadas extramuros. En este sentido, la distribución de $\mathrm{F}$

\section{Colores en las Barbacanas}
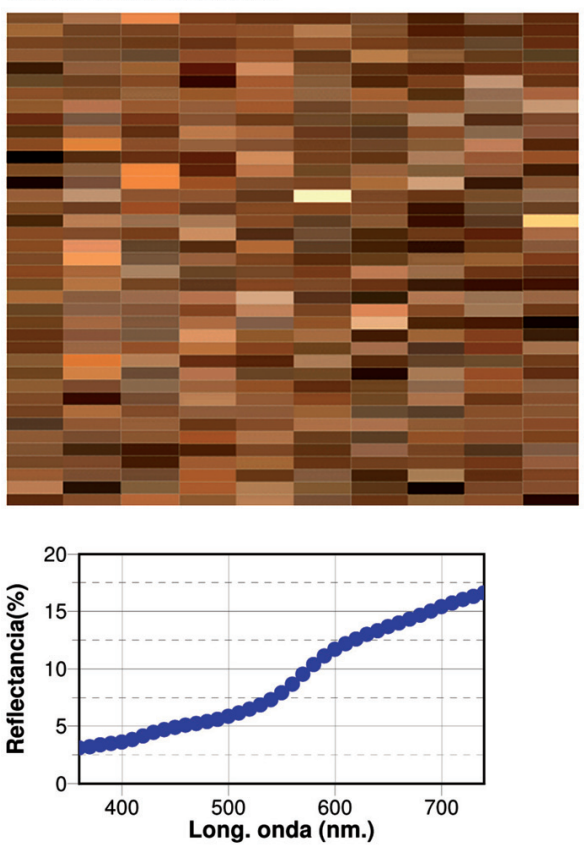

20. Colores aparentes de las muestras cromáticas tomadas en las barbacanas y su proporción por familias en notación Munsell.

21. Representación espectral del color medio obtenido en las barbacanas. Variación de la luminosidad en las distintas muestras.

22. Representación en sistema CIE L*ab de los colores de las muestras cromáticas tomadas en las barbacanas.

$\begin{array}{cc}\text { familia } & \text { proporción } \\ \text { 0Y } & 1 \% \\ \text { 10 YR } & 1 \% \\ 5 \text { YR } & 0,5 \% \\ 6 \text { YR } & 2 \% \\ 6,5 \text { YR } & 3 \% \\ \text { 7YR } & 10 \% \\ 7,5 \text { YR } & 20 \% \\ 8 \text { YR } & 21 \% \\ 8,5 \text { YR } & 18 \% \\ 9 \text { YR } & 15 \% \\ 9,5 \text { YR } & 6 \% \\ 10 \text { YR } & 2 \%\end{array}$

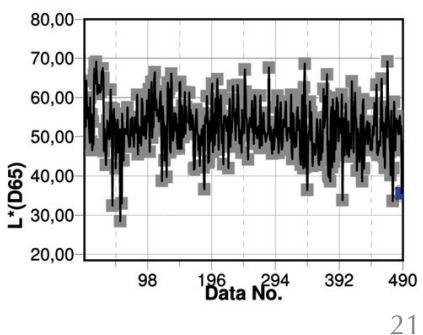

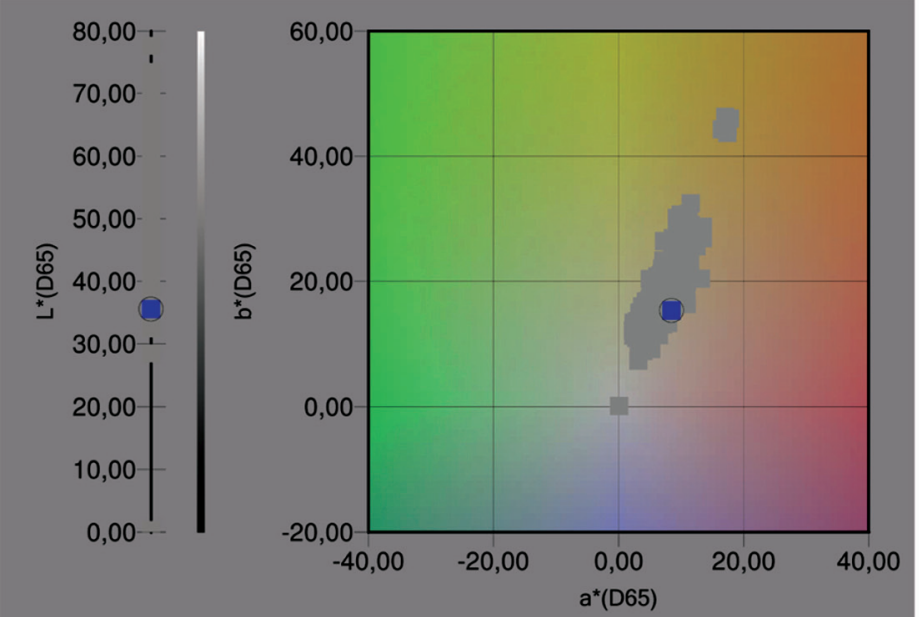

\begin{tabular}{|l|l|l|l|}
\hline Barbican. Count $=\mathbf{4 7 8}$ & $\mathbf{L}^{*}$ & $\mathbf{a}^{*}$ & $\mathbf{b}^{*}$ \\
\hline Average & 52,19 & 6,75 & 16,51 \\
\hline Standard deviation & $\Delta \mathrm{L}^{*}=6,00$ & $\Delta \mathbf{a}^{*}=1,87$ & $\Delta \mathbf{b}^{*}=3,72$ \\
\hline Minimum & 28,45 & 2,3 & 7,32 \\
\hline Maximum & 68,61 & 13,48 & 32,42 \\
\hline Average Col
\end{tabular}

Average Colour in Munsell notation: $8 \mathrm{YR} / 5 / 3 ; \Delta E=7,30$
Frequency Tabulation for I

\begin{tabular}{crrrrr} 
& $\begin{array}{c}\text { Lower } \\
\text { Class }\end{array}$ & $\begin{array}{c}\text { Upper } \\
\text { Limit }\end{array}$ & Midpoint & Frequency & $\begin{array}{l}\text { Relative } \\
\text { Frequency }\end{array}$ \\
\hline at or below & 26,0 & & 0 & 0,0000 \\
1 & 26,0 & 33,3333 & 29,6667 & 3 & 0,0063 \\
2 & 33,3333 & 40,6667 & 37,0 & 12 & 0,0251 \\
3 & 40,6667 & 48,0 & 44,3333 & 84 & 0,1757 \\
4 & 48,0 & 55,3333 & 51,6667 & 256 & 0,5356 \\
5 & 55,3333 & 62,6667 & 59,0 & 101 & 0,2113 \\
6 & 62,6667 & 70,0 & 66,3333 & 22 & 0,0460 \\
above & 70,0 & & & 0 & 0,0000
\end{tabular}

Frequency Tabulation for a

\begin{tabular}{cccccc} 
& $\begin{array}{c}\text { Lower } \\
\text { Class } \\
\text { Limit }\end{array}$ & $\begin{array}{c}\text { Upper } \\
\text { Limit }\end{array}$ & Midpoint & Frequency & $\begin{array}{l}\text { Relative } \\
\text { Frequency }\end{array}$ \\
\hline at or below & 0,0 & 0,0 & & 0 & 0,0000 \\
1 & 0,5 & 1,25 & 3 & 0,0063 \\
2 & 2,5 & 5,0 & 3,75 & 75 & 0,1569 \\
3 & 5,0 & 7,5 & 6,25 & 242 & 0,5063 \\
4 & 7,5 & 10,0 & 8,75 & 137 & 0,2866 \\
5 & 10,0 & 12,5 & 11,25 & 18 & 0,0377 \\
6 & 12,5 & 15,0 & 13,75 & 3 & 0,0063 \\
above & 15,0 & & & 0 & 0,0000
\end{tabular}

Frequency Tabulation for $b$

\begin{tabular}{cccccc} 
& $\begin{array}{c}\text { Lower } \\
\text { Class } \\
\text { Limit }\end{array}$ & $\begin{array}{c}\text { Upper } \\
\text { Limit }\end{array}$ & Midpoint & Frequency & $\begin{array}{l}\text { Relative } \\
\text { Frequency }\end{array}$ \\
\hline at or below & 7,0 & & 0 & 0,0000 \\
1 & 7,0 & 12,5 & 9,75 & 53 & 0,1109 \\
2 & 12,5 & 18,0 & 15,25 & 305 & 0,6381 \\
3 & 18,0 & 23,5 & 20,75 & 98 & 0,2050 \\
4 & 23,5 & 29,0 & 26,25 & 15 & 0,0314 \\
5 & 29,0 & 34,5 & 31,75 & 7 & 0,0146 \\
6 & 34,5 & 40,0 & 37,25 & 0 & 0,0000 \\
above & 40,0 & & & 0 & 0,0000
\end{tabular}


23. Mapas de Sombras: 1-Alzado del Portal de acceso. 2.-Sección por el portal en dirección Norte.

3.-Alzado de la Torre Sur. 4.-Sección por el Portal en dirección Sur.

5.-Alzado de la Torre Norte. sobre el modelo, y por tanto la duración de los periodos de insolación viene determinado, en gran medida, por la orientación geográfica de las Torres y el despliegue de sombras arrojadas que el propio edificio genera sobre sí mismo. En este sentido, cabe hacer una consideración sobre el entorno de las Torres y su influencia en los valores de F. En la actualidad, el entorno próximo de las torres (y en concreto su flanco oeste, que es el que nos atañe) está ocupado por edificaciones de altura considerable (planta baja más siete alturas), pero estas edificaciones son relativamente recientes en comparación con el tiempo que las Torres Ilevan construidas. Aunque siempre hubo edificaciones en las inmediaciones, hasta hace aproximadamente cincuenta años, dichas edificaciones no tuvieron relevancia respecto a las sombras que pudieran arrojar sobre las Torres de Quart, pues su altura era sólo la correspondiente a la planta baja más una. Por ello, a efectos del cálculo del Factor de Obstrucción Solar, no se ha considerado la repercusión de las sombras arrojadas por los edificios del entorno sobre la superficie extramuros del monumento.

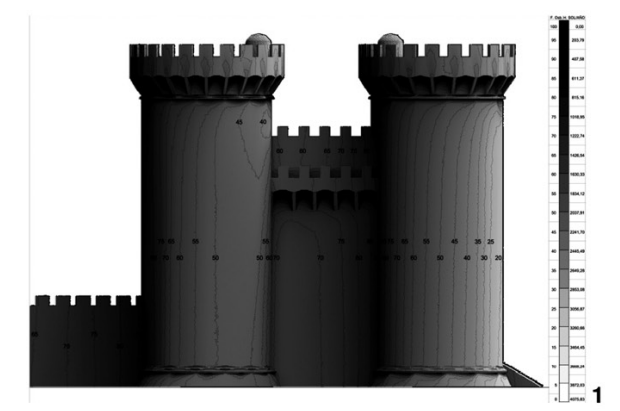

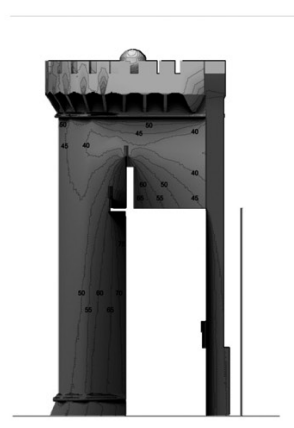

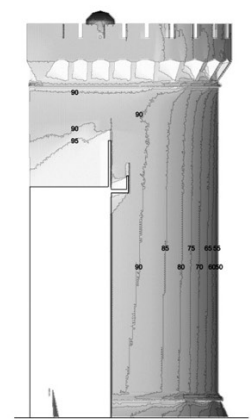

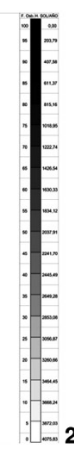
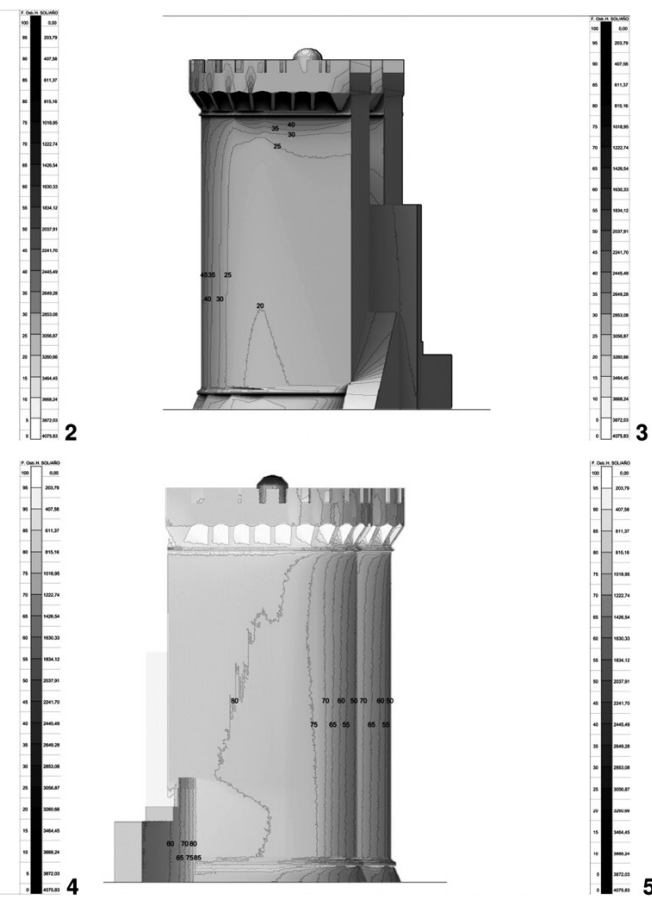

El cálculo del valor del Factor de Obstrucción Solar sobre todos los puntos de la superficie extramuros requiere de la obtención de un número suficiente de mapas de sombra que permitan la observación de todos ellos, sin que ninguno quede oculto por la geometría del propio edificio. El hecho de que las torres presenten una forma cóncava obliga a realizar dibujos en sección de las mismas para poder mostrar puntos de su superficie que de otro modo no se verían. A tal fin, se han desarrollado los siguientes cinco mapas de sombras:

1. Alzado del Portal de acceso: (Figura 23.1) Muestra en verdadera magnitud el paño de muro comprendido entre los volúmenes de las dos Torres. En dicho paño puede apreciarse que la distribución de $\mathrm{F}$ presenta sus valores más elevados hacia la torre norte como consecuencia de las sombras que arroja la torre sur. El valor medio del Factor de Obstrucción Solar en el paño es $F=0.75$, correspondiente a 1.018 Horas sol/año. En el alzado también se muestra la parte frontal de las dos torres en las que se observa un gradiente en el valor de $\mathrm{F}$ que indica mayor número de horas de sol cuanto más al sur se encuentre el punto considerado.

2. Sección por el portal en dirección Norte: (Figura 23.2) Muestra en verdadera magnitud el flanco norte de la torre sur. Las condiciones de soleamiento que se registran sobre este flanco son las mínimas detectadas en todas las superficies de las torres. Al hecho de su orientación norte cabe añadir que los escasos rayos de luz que pudiera recibir durante la salida y la puesta del sol en los días próximos al solsticio, se ven impedidos por la presencia del portal de acceso. Los valores del factor que se registran son $\mathrm{F}=0.95$, que equivale a 203 horas sol/año y representan el valor mínimo de soleamiento sobre la superficie extramuros.

3. Alzado de la Torre Sur: (Figura 23.3) Muestra en verdadera magnitud el flanco sur de las Torres. Este flanco presenta el valor máximo de $\mathrm{F}$ para todas las superficies extramuros de las Torres; con un valor numérico $\mathrm{F}=0.20$; equivalente a 3.260 horas sol/año. La forma cilíndrica de la Torre hace que el valor $\mathrm{F}$ vaya aumentando progresivamente a medida que la orientación de la fachada avanza desde una componente sur hacia una componente oeste (lo que se valora midiendo las componentes de un vector normal a la superficie).

4. Sección por el Portal en dirección Sur: (Figura 23.4) Muestra en verdadera mag- 
nitud el flanco sur de la torre norte. La distribución del valor de $\mathrm{F}$ en este caso se ve afectada fundamentalmente por la sombra arrojada por la torre sur y el volumen que representa el portal de acceso. En los puntos adyacentes al portal de acceso se registran los valores mínimos de $F$, con $F=0.75$, equivalente $a$ 1.018 Horas sol/año. En la parte superior del flanco expuesto los valores de $\mathrm{F}$ aumentan considerablemente, al ser menor la influencia de las sombras arrojadas. En este caso $\mathrm{F}=0.40$, equivalente a 2.445 horas sol/año.

5. Alzado de la Torre Norte: (Figura 23.5) En este caso, el flanco que se muestra en verdadera magnitud es el orientado hacia el norte. Dicho flanco sólo recibe la radiación solar a primera y última hora del día en el entorno del solsticio de verano. Por ello, los valores de F mínimos sobre los puntos de su superficie alcanzan un valor de $\mathrm{F}=0.80$, equivalente a 815 horas de sol/año. En este caso, dado que los valores obtenidos para $\mathrm{F}$ son relativamente bajos, la imagen del mapa de sombras resultaría muy oscura, por lo que se muestra con la luminosidad invertida, a efectos de que resulte inteligible. En este caso, los tonos de gris más próximos al blanco implican valores de F mayores, es decir, menor insolación.

En base a la información suministrada por estos cinco mapas de sombra se obtiene la imagen definitiva que presenta las fachadas de las Torres desarrolladas en verdadera magnitud (Figura 24). Sobre el mapa de sombras conjunto se puede apreciar el gradiente de valores de grises, que muestran con tonos más claros las zonas más expuestas al sol. Puede apreciarse cómo las zonas orientadas a sur presentan los valores máximos de exposición a la radiación solar mientras que las zonas menos expuestas se muestran en tonos más próximos al negro. Las líneas de igual valor de $\mathrm{F}$ permiten la lectura directa sobre la escala lateral de sus valores numéricos, y a partir de estos, extrapolar la duración de los periodos de incidencia solar.

La imagen así obtenida permite la comparación con la distribución en cuadrantes que ha permitido la toma de muestras cromáticas. De este modo, dentro de los cuadrantes considerados se puede registrar un valor medio de $F$, que permite relacionar los datos cromáticos con los datos de duración de la incidencia solar.

\subsection{Discusión de los resultados}

Si se realiza una valoración global de los valores cromáticos medios obtenidos, ob-

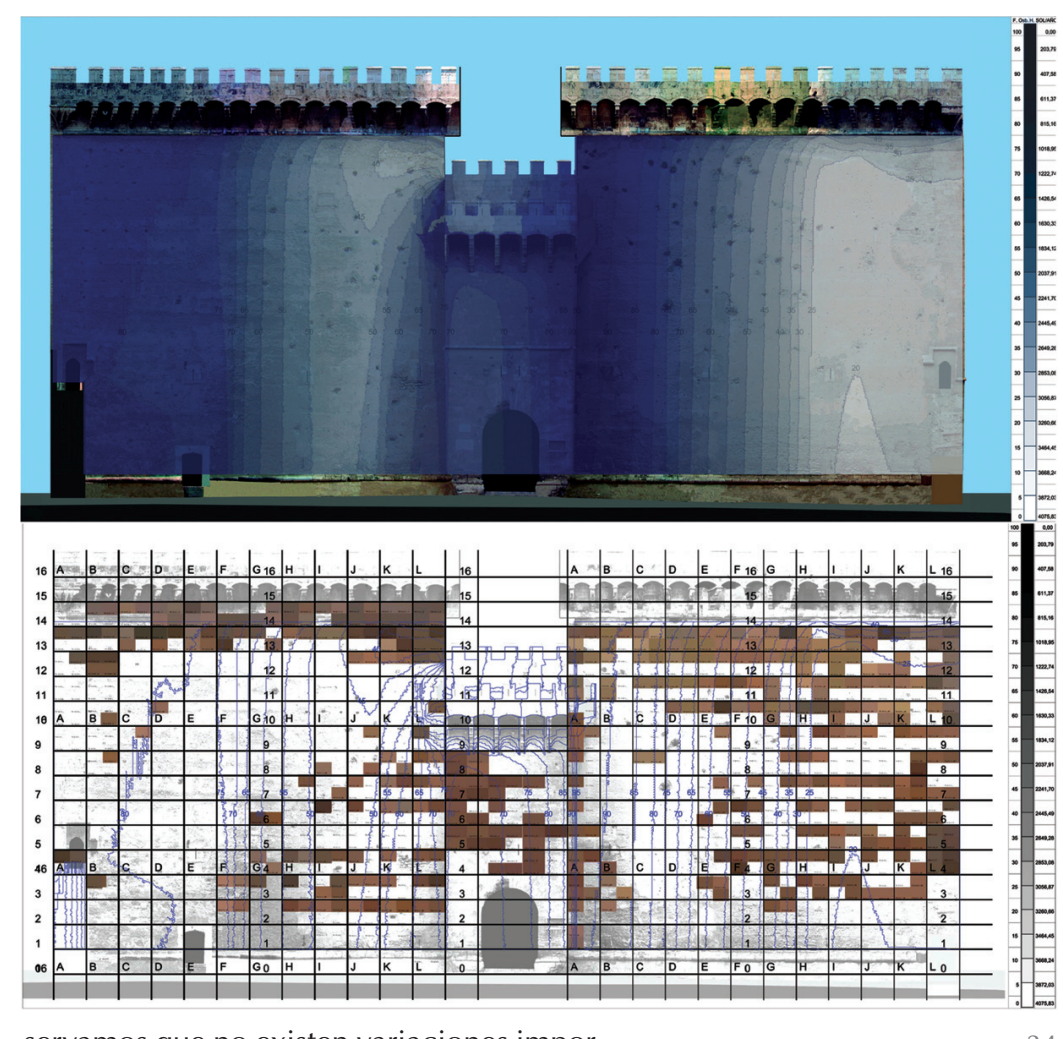

servamos que no existen variaciones importantes entre las medidas correspondientes a los distintos estratos: mortero 1, mortero 2, piedra de fachada y piedra de las barbacanas. La caracterización del color actual de las Torres de Quart puede establecerse para cada material con mucha precisión dado que la desviación estándar entre las muestras de color es muy pequeña.

Si se considera la coordenada $a^{*}$, se observa que adopta los valores más pequeños en las barbacanas, mientras que los mayores en la piedra. El tono más rojizo se encuentra en la piedra y el mortero 2, que son los más expuestos al soleamiento y los agentes atmosféricos, mientras que las barbacanas poseen los valores inferiores. Si consideramos la coordenada b*, se observa que el contenido de primario amarillo es bastante similar para todos los materiales -y algo superior al contenido del primario rojo. Los tonos más amarillentos se ubican en $\mathrm{M} 2$, que es el estrato más expuesto al soleamiento y los agentes atmosféricos, mientras que en las barbacanas presentan valores inferiores. Los tonos en las barbacanas tienen menor contenido de primarios rojo $\left(a^{*}\right)$ y amarillo $\left(b^{*}\right)$ que en otros estratos, de modo que poseen así mismo menor croma $(\mathrm{C}=\operatorname{arctg} \mathrm{b} / \mathrm{a})$ respecto a morteros y piedras.

Atendiendo a la distribución de frecuencias para la luminosidad de los colores, los valores son similares en todos los materiales, oscilando en un rango entre $L^{*}=45 \mathrm{y}$ $L^{*}=65$ (86\% M1, 84\% M2, 71\% Piedra, $89 \%$ en barbacanas) pero con una mayor 
25. Tonalidades de color medias obtenidas por estratos número de cuadrantes y superficie identificada.

26. Correlación entre las variables colorimétricas en notación Munsell $\mathrm{H}, \mathrm{V}, \mathrm{C}$ y el Factor de obstrucción solar (F) para cada estrato $\mathrm{P}, \mathrm{M} 1, \mathrm{M} 2$.

dispersión que en $a^{*} y b^{*}$. Estos valores de $\mathrm{L}^{*}$ indican colores de luminosidad intermedia, ni excesivamente oscuros ni claros.

Puede concluirse que los pigmentos en las fachadas exteriores de las Torres de Quart son colores tierra, que pertenecen principalmente a las familias de color Munsell 7YR a 8YR para cada estrato material ( $\mathrm{Fi}$ gura 25). Colores tierra con escasa saturación -consistentes en una mezcla de tonos amarillos y rojos en menor proporción. Este resultado es coherente con investigaciones

\begin{tabular}{|c|c|c|c|c|c|c|c|}
\hline Estrato & 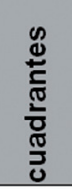 & 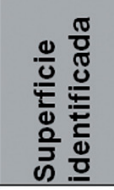 & $\begin{array}{l}\overline{0} \\
\stackrel{0}{0} \\
* \\
.\end{array}$ & $\begin{array}{l}\widehat{5} \\
\stackrel{0}{0} \\
0 \\
* \\
*\end{array}$ & 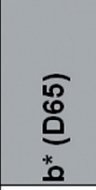 & $\begin{array}{l}\overline{\bar{d}} \\
\bar{\omega} \\
\bar{\Sigma} \\
\Sigma\end{array}$ & 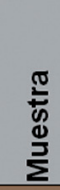 \\
\hline Mortero 1 & 22 & 29,26 & 54,49 & 7,75 & 21,93 & $8 Y R / 5,5 / 4$ & \\
\hline Mortero 2 & 271 & 360,4 & 55,91 & 8,55 & 23,61 & $8 Y R / 5,5 / 4$ & \\
\hline Piedra & 153 & 203,5 & 49,64 & 9,05 & 19,19 & $7 Y R / 5 / 4$ & \\
\hline Barbacana & 96 & 150,24 & 52,19 & 6,75 & 16,51 & $8 Y R / 5 / 3$ & \\
\hline
\end{tabular}

M2_L* vs F

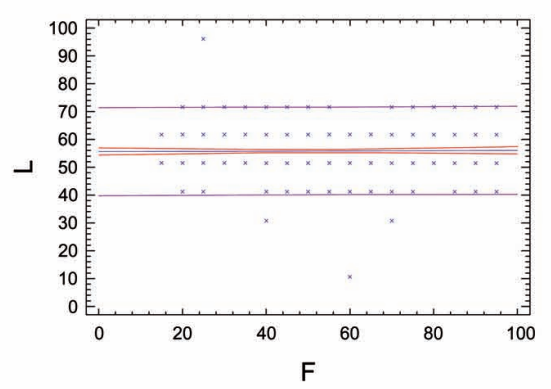

M1_L* vs F

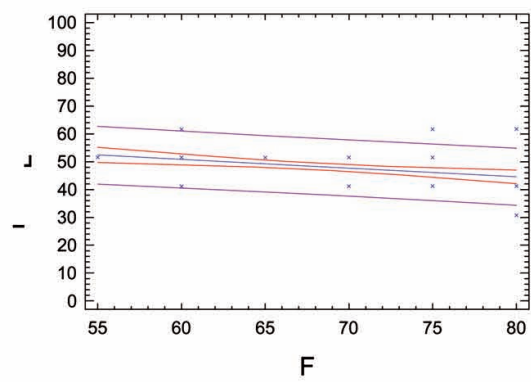

$P_{-} L^{*}$ vs $F$

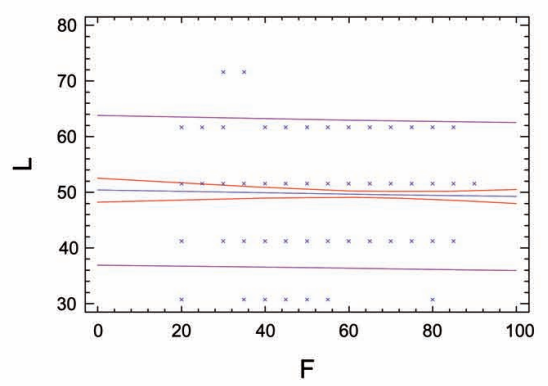

M2_a* vs F

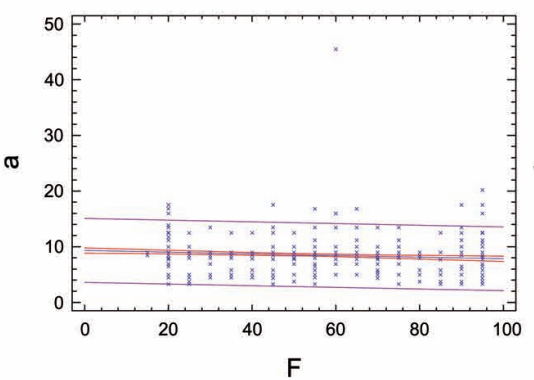

M1_a*vs F

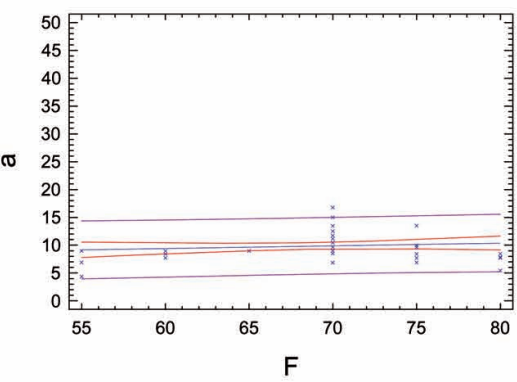

P_a* vs F

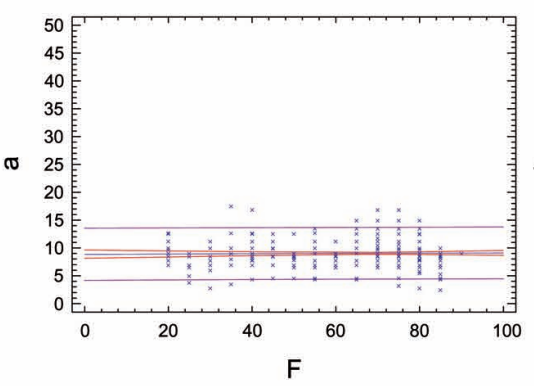

previas sobre color en los revocos antiguos de la arquitectura popular del centro histórico de Valencia $(6,7)$.

A partir de la distribución espacial de los valores $\mathrm{L}$, a y b; y del valor de F (Factor de obstrucción) para los mismos puntos de la superficie extramuros, se ha tratado de encontrar alguna relación entre los valores medidos y calculados.

La estrategia de comparación es la siguiente: elegido un sustrato material (por ejemplo, M1) y una de sus tres coordenadas en Lab* (por ejemplo, a*), se ha generado una tabla donde se relaciona el valor de $\mathrm{a}^{*}$ con el valor de $\mathrm{F}$ para cada cuadrante de la fachada. Definida esta serie de datos se calcula el coeficiente de correlación lineal que relaciona ambas variables.

La comparación se efectúa para cada sustrato material con respecto a cada uno de los valores Lab con el valor F, cuadrante a cuadrante (Figura 26). Se calcula de este modo el coeficiente de correlación lineal (r), que permite estudiar distribuciones bidimensionales e indicar la intensidad o grado de dependencia entre las variables estudiadas. El coeficiente

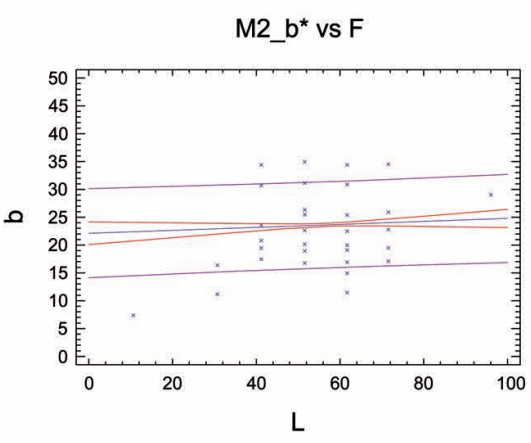

M1_b* vs F

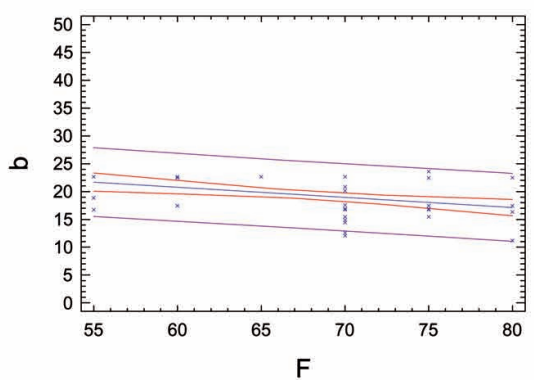

P_b* vs F

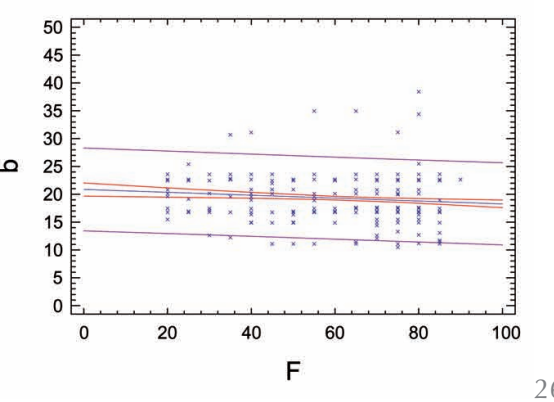


de correlación adquiere valores absolutos comprendidos entre cero y uno, siendo el valor de $r$ igual a uno cuando la correlación lineal es perfecta y el valor de $r$ igual a cero cuando existe una independencia total entre los valores a estudiar (Figura 27).

Las series de variables estudiadas, para cada uno de los estratos materiales, presenta los siguientes valores del coeficiente de correlación:

\begin{tabular}{|l|l|l|}
\hline Sustrato & Variable/factor & Correlación $(\boldsymbol{r})$ \\
\hline \multirow{3}{*}{$\begin{array}{l}\text { Mortero 1 } \\
\text { (M1) }\end{array}$} & $\mathrm{L}^{*} / \mathrm{F}$ & $\mathrm{e}=0,11853970$ \\
\cline { 2 - 3 } & $\mathrm{a}^{*} / \mathrm{F}$ & $\mathrm{e}=0,36711121$ \\
\cline { 2 - 3 } & $\mathrm{b}^{*} / \mathrm{F}$ & $\mathrm{e}=0,07683693$ \\
\hline \multirow{3}{*}{$\begin{array}{l}\text { Mortero 2 } \\
\text { (M2) }\end{array}$} & $\mathrm{L}^{*} / \mathrm{F}$ & $\mathrm{e}=0,024480419$ \\
\cline { 2 - 3 } & $\mathrm{a}^{*} / \mathrm{F}$ & $\mathrm{e}=0,10022973$ \\
\cline { 2 - 3 } & $\mathrm{b}^{*} / \mathrm{F}$ & $\mathrm{e}=-0,237459190$ \\
\hline \multirow{3}{*}{$\begin{array}{l}\text { Piedra } \\
\text { (P) }\end{array}$} & $\mathrm{L}^{*} / \mathrm{F}$ & $\mathrm{e}=0,011354964$ \\
\cline { 2 - 3 } & $\mathrm{a}^{*} / \mathrm{F}$ & $\mathrm{e}=-0,00988276$ \\
\cline { 2 - 3 } & $\mathrm{b}^{*} / \mathrm{F}$ & $\mathrm{e}=-0,1618578$ \\
\hline
\end{tabular}

Dado que los valores obtenidos para el coeficiente de correlación son muy próximos a cero, puede concluirse que para cada variable cromática y cada sustrato material no existe una correlación significativa. Este hecho implica que la distribución de los valores de las variables cromáticas estudiadas sobre la superficie extramuros no se ve influida por la exposición al Sol. Una mayor exposición a la luz solar no ha causado una variación detectable cromáticamente en el contenido de los tonos primarios rojo/ amarillo, en la luminosidad o en la saturación de los pigmentos inorgánicos. El soleamiento no es un factor relevante en las diferencias detectadas en los valores de los parámetros cromáticos encontrados en los pigmentos a lo largo de las fachadas exteriores, y estos cambios deben haber sido inducidos por otros agentes de deterioro.

\section{CONCLUSIONES}

Como resultado de este análisis de los restos de pigmentos encontrados en las fachadas extramuros de las Torres de Quart de Valencia, sobre tres estratos materiales de distinta naturaleza (mortero 1, mortero 2 y piedra), y el efecto del soleamiento sobre sus parámetros cromáticos, se ha obtenido un documento gráfico preciso del estado del color y su iluminación previo a la intervención arquitectónica. Un registro necesario para la intervención arquitectónica, como recomiendan varios estudios sobre restauración desde finales del s. XIX -Camilo Boito (1836-1914), en la Carta de Venecia (1964) (8) y en las sucesivas Cartas de Restauración a lo largo del s. XX (9)-.

Respecto a la caracterización de los colores en las fachadas exteriores de las Torres, esta investigación concluye que los pigmentos existentes son colores terrosos, consistentes en una mezcla de amarillo, con contenido de primario rojo en menor proporción (con predominio de las familias de color Munsell 7 YR a 8 YR), con luminosidad media y poca saturación, para cada estrato material. Estos resultados son coherentes con investigaciones previas sobre el color en los revocos antiguos de los edificios del centro histórico de Valencia.

Los menores contenidos absoluto y relativo de primario rojo $\left(a^{*}\right)$ y amarillo $\left(b^{*}\right)$ se encuentran en las barbacanas, que se han visto menos expuestas a la luz solar que otros materiales, mientras que el mortero M2 y la piedra, con más incidencia solar, presentan los valores mayores de contenido absoluto y relativo de $\mathrm{a}^{*} \mathrm{y} \mathrm{b}^{*}$. Dado que estadísticamente se ha determinado la inexistencia de una relación directa entre los valores de las variables cromáticas estudiadas sobre la superficie extramuros con la diferente exposición al sol, cabe exponer la hipótesis de que la preservación del color en las barbacanas es producto no tanto de la exposición solar como de la menor exposición a otros agentes agresivos propios de la circulación, polución, agresión de viandantes, etc. Además, se han comparado los parámetros cromáticos con el factor de obstrucción solar (F), que evalúa la exposición a la luz solar, para cada estrato material, y no se ha encontrado ninguna correlación lineal significativa entre ambos: parámetros de color y exposición solar. Las variaciones en el contenido de primarios rojo/amarillo, la claridad del color o su croma, deben haber sido causadas por otros agentes de deterioro, pero no por la cantidad de luz recibida a lo largo de los años en las fachadas exteriores de las Torres de Quart, como podía esperarse a priori. La incidencia de la luz solar no ha sido un agente de deterioro significativo en el color de las fachadas exteriores de las Torres de Quart. Esta alta resistencia del color a los efectos de la exposición solar, caracteriza los morteros coloreados con pigmentos minerales frente a los tratamientos cromáticos industriales actuales, y constituye una base para las intervenciones de restauración en edificios de estas características materiales.

Este estudio no se había realizado nunca con anterioridad sobre el monumento y entendemos que puede ser útil para investigaciones futuras sobre el deterioro del color arquitectónico. Al tiempo ha permitido la aproximación más exacta posible para conocer la pigmentación de color de las Torres de Quart y su información ha sido muy útil para producir una visualización definitiva, posibilitando la toma de decisiones sobre el acabado superficial para la restauración arquitectónica.
27. Valor del coeficiente de correlación lineal (r) entre las variables cromáticas en notación Munsell H, V, C y el Factor de Obstrucción Solar (F) para cada sustrato material. 


\section{BIBLIOGRAFÍA}

(1) Zaragoza, A. et al.: Pere Compte, Arquitecto. p. 428, Consorcio de Museos de la Comunitat Valenciana, Valencia, 2007.

(2) Piles Selma, V. et al.: "Estudio de los morteros de los revestimientos continuos de las arquitecturas del centro histórico de valencia: preparación de morteros de restauración mixtos cal-puzolana", Tesis doctoral, inédita, Universidad Politécnica de Valencia, p. 221, Valencia, 2007.

(3) Kuehni, R. G.: "The early development of the Munsell system". Color Research and Application, 27 (1): 20-27, February 2002. doi:10.1002/col.10002.

(4) Higón Calvet, J. L.; Ferrer Gila, J. J.: "Contribuciones al estudio del asoleo geométrico: procedimientos para el cálculo del factor de obstrucción solar: aplicaciones". Tesis doctoral, inédita, Universidad Politécnica de Valencia, Valencia, 2003.

(5) Fairchild, M. D.: "Color and Image Appearance Models". Color Appearance Models. p. 340, John Wiley and Sons, 2005.

(6) García Codoñer, A. et al.: "El color del centro histórico: arquitectura histórica y color en el barrio del Carmen de Valencia", p. 109, Ajuntament de València, Valencia, 1995.

(7) García Codoñer, A. et al.: "El color en el barrio de Velluters", p.183, Ajuntament de València, Valencia, 2000.

(8) Martínez Justicia, M. J.: "Carta del restauro 1987", p. 70, Colegio de Arquitectos, Málaga, 1990.

(9) ICOMOS: "Il restauro in italia e la carta di Venezia: atti del convegno", ICOMOS, p. 196. Edizioni Scientifiche Italiane, Napoli-Ravello, 28 Sett. -1 Ott. 1977. 